\title{
RECOMENDAÇÃO DE ESPÉCIES ARBÓREAS NATIVAS, POR TIPO DE SOLO, PARA RECUPERAÇÃO AMBIENTAL DAS MARGENS DA REPRESA DO RIO IRAÍ, PINHAIS, PR
}

\author{
Gustavo Ribas Curcio*, Letícia Penno de Sousa**, Annete Bonnet***, Murilo Lacerda Barddal**** \\ *Eng. Agrônomo, Dr., Embrapa Florestas - curcio@cnpf.embrapa.br \\ **Eng ${ }^{\text {a }}$ Florestal, M.Sc., Embrapa Florestas - leticia@cnpf.embrapa.br \\ ***Bióloga, Dr ${ }^{\mathrm{a}}$., Pós-Douroranda em Eng. Florestal, UFPR - a_bonnet@hotmail.com \\ ****Eng. Florestal, Dr., COPEL - murilo.barddal@copel.com \\ Recebido para publicação: 03/07/2006 - Aceito para publicação: 27/09/2006
}

\begin{abstract}
Resumo
A construção de reservatórios de água próximos aos grandes centros urbanos é uma realidade crescente nos dias atuais. Esse tipo de empreendimento, em geral, causa forte supressão de florestas fluviais, gerando, portanto, a necessidade de plantios logo acima da cota de máxima inundação que venham a compensar a mencionada supressão. Este trabalho tem por objetivo recomendar espécies arbóreas nativas para plantios, considerando grau de adaptabilidade dessas ao nível de hidromorfia dos solos presentes nas paisagens circunjacentes ao reservatório do rio Iraí, localizado no município de Pinhais, Paraná.

Palavras-chave: Espécies arbóreas; recuperação ambiental; solos.
\end{abstract}

\section{Abstract}

Native arboreal species recommended, by soil types, for environmental reclamation of river banks on Irai river dam, Pinhais, $P R$. The building of water sinks next to big urban centers is an increasing reality nowadays. This type of undertaking generally causes great pression on riparian forests, out coming the necessity of planting just above maximum reference of flooding that can compensate that vegetation's suppression. This work aims to recommend the selection of native trees species for plantations, considering its adaptation to the soil hidromorphy level of the landscapes bounding to the Iraí water sink, located in Pinhais, Paraná State.

Keywords: Arboreal species; environmental reclamation; soils.

\section{INTRODUÇÃO}

O estado do Paraná possui expressividade fitogeográfica bastante acentuada, com florestas entremeadas por formações herbáceas e arbustivas, determinadas por características climáticas, geomorfológicas e pedológicas (RODERJAN et al., 2002). Originalmente, o Estado possuía $85 \%$ da sua superfície coberta por formações florestais, sendo o Primeiro Planalto ocupado por florestas, ocorrendo ainda próximo à cidade de Curitiba a presença de campos (MAACK, 1981) ou estepes (RODERJAN et al., 2002), em dimensões geográficas bem menos expressivas.

Normalmente, para o referido Estado, os corpos de água são circundados por fitotipias florestais, no entanto, no Segundo Planalto, em condições originais, encontravam-se algumas lentes d'água com campos circunjacentes, situação não identificada no Primeiro Planalto, onde as florestas perfaziam esses ambientes.

O modelo de desenvolvimento socioeconômico empregado até os dias atuais colide, frontalmente, com a necessidade de preservação e conservação de ecossistemas. Como conseqüência, observa-se atualmente uma condição crescente de declínio da qualidade dos recursos naturais, especialmente das águas superficiais, tão importantes para a manutenção de vida (MIRANDA, 2004). Nesse sentido, deve ser salientado que, tanto nas zonas urbanas como nas rurais, são diversos os fatores 
que contribuem para a depreciação desse recurso, tais como: lixo, esgoto, dejetos industriais, resíduos de pocilgas, insumos agrícolas e sedimentos oriundos de processos erosivos existentes, entre outros.

Ao mesmo tempo, verifica-se que o crescimento desordenado das cidades aumenta substancialmente a demanda de água potável, fato também identificado para a região da grande Curitiba, a qual já necessita do represamento de alguns rios para seu abastecimento hídrico, tais como Passaúna e Iraí.

$\mathrm{O}$ reservatório do rio Iraí, pertencente à bacia hidrográfica do rio Iguaçu, abrange três municípios paranaenses integrantes da região metropolitana de Curitiba (Pinhais, Piraquara e Quatro Barras) e tem por finalidade suprir, com seus $58.000 .000 \mathrm{~m}^{3}$, a demanda hídrica da citada região (CARNEIRO et al., 2005).

As estepes, unidade fitogeográfica na qual a área de estudo está inserida, eram constituídas originalmente por formações herbáceas que cobriam as encostas e agrupamentos arbóreos associados aos cursos d'água (RODERJAN et al., 2002).

Naturalmente, o rio Iraí apresentava uma floresta ripária com diversidade considerável para as condições de planície (ZILLER, 1995), dados muito semelhantes aos encontrados por outros autores em rios da região (BUFREM, 1997; BARDDAL, 2002; BARDDAL et al., 2003; PASDIORA, 2003).

A formação do reservatório levou a um comprometimento total da floresta ripária dentro da área do empreendimento, gerando, como conseqüência, forte pressão sobre as fitotipias relictas de capões ainda existentes nas áreas circunjacentes. Complementarmente, a cota máxima de inundação do reservatório - 888,70 m (Figura 1) - atinge em grande parte campos nativos mesófilos (sobre solos nãohidromórficos), proporcionando, em sua borda, a descaracterização da legitimidade hídrica original desses ambientes. Afeta também, em menor abrangência geográfica, os campos higrófilos (sobre solos semi-hidromórficos).

Com o objetivo de orientar, de acordo com o nível de hidromorfia dos solos, os futuros plantios de espécies arbóreas nativas em uma faixa de $30 \mathrm{~m}$ de largura ao redor do reservatório do rio Iraí, compensando parcialmente a supressão das florestas fluviais originais e, conseqüentemente, minimizando a pressão sobre os capões remanescentes, apresenta-se essa recomendação. Em virtude dos plantios serem efetuados sobre campos nativos, o que necessariamente poderia ser caracterizado como uma segunda forma de supressão e impacto, devem ser evitadas as áreas mais conservadas dessa fitotipia.

\section{MATERIAIS E MÉTODOS}

\section{Caracterização da área}

O reservatório do rio Iraí atinge três municípios integrantes da região metropolitana de Curitiba (Pinhais, Piraquara e Quatro Barras, estado do Paraná), sobre as coordenadas de $25^{\circ} 24^{\prime} \mathrm{S}$ e $49^{\circ} 08^{\prime} \mathrm{W}$, a 890 metros de altitude.

$\mathrm{O}$ clima da região, segundo Köppen, é subtropical mesotérmico úmido $(\mathrm{Cfb})$, com temperatura média do mês mais frio inferior a $18{ }^{\circ} \mathrm{C}$, temperatura média do mês mais quente inferior a $22^{\circ} \mathrm{C}$ e sem estação seca definida (IAPAR, 1994).

Segundo Roderjan et al. (2002), a vegetação ocorrente na região se enquadra na unidade fitogeográfica Floresta Ombrófila Mista, na qual coexistem representantes da flora tropical e temperada, com predomínio da Araucaria angustifolia (Bertol.) Kuntze. Nessa unidade, encontra-se inserida uma formação natural de campos, citada por Maack (1981), com presença de capões constituídos por flora típica da Floresta Ombrófila Mista.

A área de estudo envolve tanto superfícies holocênicas de origem fluvial como paisagens desenvolvidas sobre a Formação Guabirotuba, formada por argilitos, arcósios, depósitos rudáceos e caliche, de idade pliopleistocênica, depositados em grandes leques aluviais sob clima semi-árido (BIGARELLA et al., 1961; BIGARELLA; SALAMUNI, 1962).

\section{Metodologia}

Para desenvolver o procedimento metodológico de forma a atender às condições de adaptação das futuras plantas arbóreas nativas a serem plantadas às condições hídricas dos solos, partiu-se do pressuposto de que a paisagem pode ser subdividida em três compartimentos, de acordo com o nível do lençol freático: solos hidromórficos, semi-hidromórficos e não-hidromórficos. Os primeiros têm sua formação relacionada a elevados níveis de saturação hídrica, enquanto os não-hidromórficos, de forma contrastante, possuem desenvolvimento pedogenético em condições de drenagem livre, em seção de 
1 metro de profundidade. Os solos semi-hidromórficos, transicionais, apresentam cores acinzentadas e/ou mosqueados decorrentes de saturação hídrica temporária/permanente entre 0,5 e $1 \mathrm{~m}$ de profundidade. De acordo com Curcio (2006), as espécies arbóreas adaptadas a essas três condições são assim conceituadas: hidrófila - adjetivação aplicada às espécies botânicas que apresentam desenvolvimento normal sobre solos hidromórficos (classes: imperfeitamente drenados, mal e muito mal drenados). As espécies hidrófilas podem apresentar desenvolvimento aparentemente normal em solos semi-hidromórficos e nãohidromórficos; higrófila - adjetivação aplicada à cobertura vegetal que apresenta desenvolvimento normal sobre solos semi-hidromórficos (classe: moderadamente drenados), nos quais a altura do lençol freático, ou mesmo a franja capilar, atinge com freqüência a profundidade de 50 a $100 \mathrm{~cm}$. As espécies suportam maiores tempos de saturação hídrica plena, além de maiores freqüências do que as espécies mesófilas. As espécies higrófilas podem ter bom desenvolvimento em solos não-hidromórficos e péssimo desenvolvimento ou mesmo alta mortalidade em solos hidromórficos; mesófila - adjetivação aplicada às espécies botânicas que se desenvolvem sobre solos não-hidromórficos (classes: bem a excessivamente drenados), podendo eventualmente conter a presença de fluxos hídricos subsuperficiais, contudo abaixo da profundidade de $100 \mathrm{~cm}$. Esse tipo de vegetação suporta períodos curtos (poucos dias) de saturação hídrica plena, desde que em baixa recorrência.

Para atender à relação acima pressuposta, foi primeiramente efetuado levantamento de solos detalhado na área demarcada na figura 1, com vistas a identificar três grupamentos de solos: hidromórficos, semi-hidromórficos e não-hidromórficos. A ação foi fundamentada em características morfológicas dos solos e textura ao tato, contudo amparada por dados analíticos (CURCIO et al., não publicado). Deve ser ressaltado que o levantamento de solos ocorreu a partir da cota máxima de inundação, dentro do limite de 30 metros, em uma extensão de $5 \mathrm{~km}$, determinando uma área de 15 ha (Figuras 1 e 2). O plantio de espécies arbóreas nativas na citada faixa de $30 \mathrm{~m}$ satisfaz as exigências da legislação ambiental (BRASIL, 1999; CONSELHO NACIONAL DO MEIO AMBIENTE, 2002) para os meios urbanos. No levantamento foram observadas as formas das paisagens, em especial o declive e a forma das rampas. Dessa maneira, foi concebida uma compartimentação geomorfológica e pedológica do entorno da represa, de forma a atender às exigências hídricas das espécies a serem recomendadas.

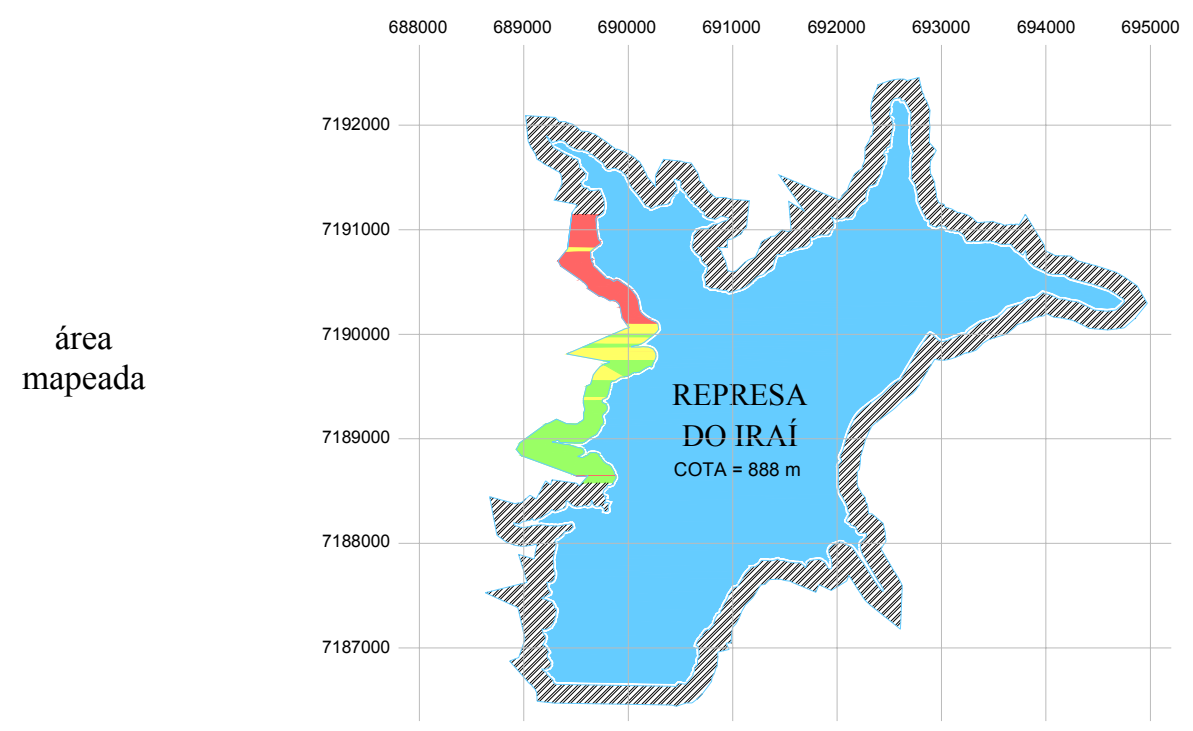

Figura 1. Cota máxima de inundação da represa do rio Iraí.

Figure 1. Maximum flooding level on Iraí river dam.

A forma de caminhamento adotada para o levantamento de solos foi toposseqüencial, sendo cada uma instituída de acordo com as características das rampas e tipos de solos. Dentro da faixa de $30 \mathrm{~m}$, em cada toposseqüência, foram feitas prospecções a partir da lâmina d'água, nas seguintes metragens: 1, 5, 10, 15, 20 e 30 m. Nessas, foram avaliadas as características morfológicas dos solos, das quais destacam-se: os 
tipos e espessuras de horizontes superficiais e subsuperficiais, presença de gleização e mosqueados, textura ao tato, além da determinação da altura do lençol freático através de poços hídricos (Figuras 4, 6 e 8).

Todo o procedimento do levantamento de solos teve as coordenadas determinadas por GPS (Global Positioning System), marca Trimble, modelo GeoExplorer 3, de precisão de 1 a 5 metros no pósprocessamento. Como material básico para o levantamento de campo, foram utilizadas fotografias aéreas coloridas escala 1:8.000, pertencentes ao programa Paranacidade, bem como ortofotos do ano 2.000, de propriedade da Suderhsa, na escala 1:10.000.

Com o objetivo de caracterizar o grau de adaptabilidade das espécies arbóreas nativas aos regimes hídricos de solos, para posterior recomendação de plantio, foi efetuado um levantamento florístico em capões remanescentes, situados nas margens da represa, procedendo-se preliminarmente uma compartimentação ambiental baseada em critérios pedológicos e geomorfológicos. Assim, as superfícies dos capões foram divididas em posição de cimeira, intermediária e de planície fluvial. Em cada superfície foram identificados os tipos de solos com base em características morfológicas e texturais (ao tato). Para se obter um maior rigor na recomendação das espécies no que se refere à adaptabilidade ao nível de hidromorfia dos solos, foram registrados somente os indivíduos com DAP $\geq 5 \mathrm{~cm}$ e em bom estado fitossanitário.

\section{RESULTADOS E DISCUSSÕES}

No levantamento de solos, efetuado em áreas circunjacentes ao reservatório do rio Iraí (Figura 2) foram encontradas seis classes de solos (Tabela 1), as quais, de forma simplificada, constituíram três compartimentos ambientais: $\mathrm{H}$ - hidromórficos, $\mathrm{SH}$ - semi-hidromórficos e $\mathrm{NH}$ - não-hidromórficos.

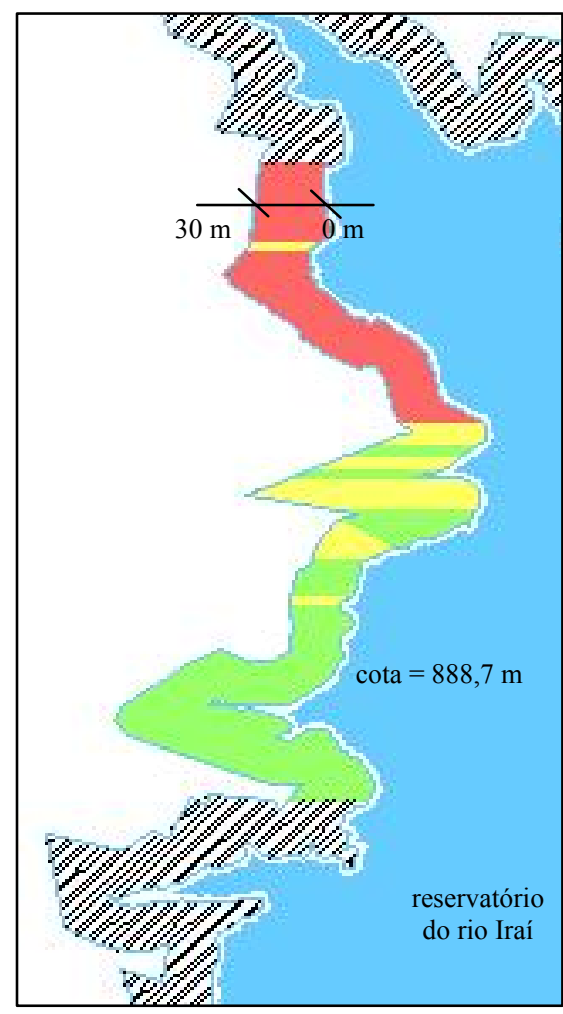

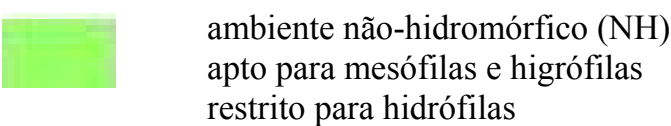

restrito para hidrófilas

ambiente semi-hidromórfico (SH)

apto para higrófilas

restrito para mesófilas

Figura 2. Compartimentos ambientais quanto ao grau de hidromorfia e fitotipias recomendadas para plantio nas áreas circunjacentes da represa do rio Iraí.

Figure 2. Environmental compartments related to hydromorphic level and plant species indicated for planting on adjacents areas of Iraí river dam. 
As classes de solos constituintes dos três ambientes constam na tabela 1.

Tabela 1. Classes de solos, formação de ambientes por nível de hidromorfia e símbolos. Table 1. Soil classes, habitats formation by hydromorphic level and symbols.

\begin{tabular}{lcc}
\hline Ambientes & Classes de solos & Simbologia \\
\hline Hidromórficos & $\begin{array}{c}\text { Organossolo Mésico Sáprico térrico relevo plano } \\
\text { Gleissolo Melânico Ta Distrófico típico Hístico textura argilosa relevo plano } \\
\text { Gleissolo Melânico Ta Distrófico típico A húmico textura argilosa relevo } \\
\text { plano }\end{array}$ & $\mathrm{H}$ \\
\hline Semi-hidromórficos & Cambissolo Húmico Tb Distrófico gleico textura argilosa relevo suave \\
ondulado & $\mathrm{SH}$ \\
\hline Não-hidromórficos & $\begin{array}{c}\text { Cambissolo Húmico Tb Distrófico típico textura argilosa relevo ondulado } \\
\text { Cambissolo Háplico Tb Distrófico típico A proeminente textura argilosa } \\
\text { relevo forte ondulado }\end{array}$ & $\mathrm{NH}$ \\
\hline
\end{tabular}

O ambiente H é dominantemente hidromórfico (Figura 2), ou seja, constituído por Organossolos e Gleissolos Melânicos em declividades iguais ou inferiores a 3\%, e é apto essencialmente para espécies hidrófilas. Em algumas localidades, há uma possibilidade muito restrita de ocupação por espécies higrófilas entre as distâncias de 25 a 30 metros da lâmina d'água (Figura 3).

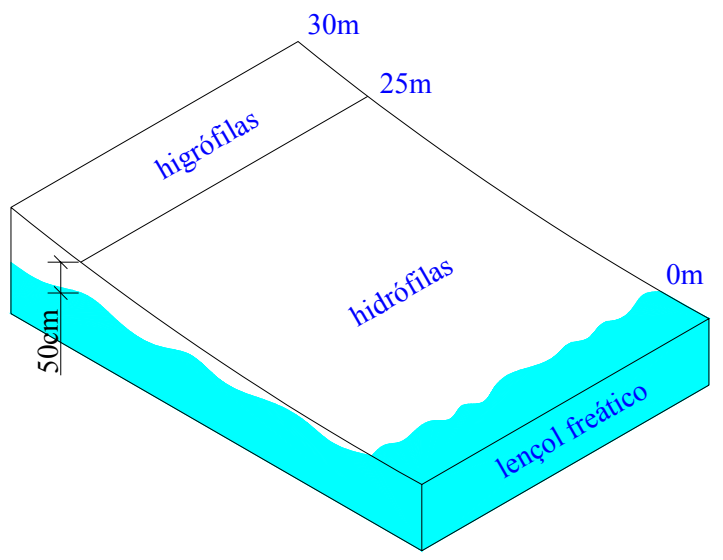

Figura 3. Representação esquemática do lençol freático no ambiente hidromórfico $(\mathrm{H})$ e indicação de fitotipias.

Figure 3. Schematic representation of water table on hydromorphic environment $(\mathrm{H})$ and plants groups recomended.

Quando o nível da represa atinge a cota máxima nesse ambiente, o lençol freático fica grande parte do tempo muito próximo da superfície do solo em toda a faixa de $30 \mathrm{~m}$, conforme pode ser observado na figura 4, tornando-o muito restrito ao desenvolvimento de espécies arbóreas, concordando com afirmações de vários autores (KOZLOWSKI, 1984; BRINSON, 1990; CASANOVA; BROCK, 2000; BARDDAL, 2002; CURCIO, 2006).

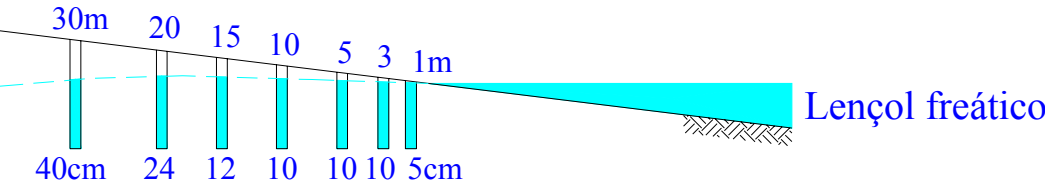

Figura 4. Altura do lençol freático na faixa de $30 \mathrm{~m}$ no ambiente hidromórfico $(\mathrm{H})$.

Figure 4. Water table level on $30 \mathrm{~m}$ strip width on hydromorphic environment. 
Na figura 4, pode ser observado que na distância de $30 \mathrm{~m}$ o lençol freático está a $40 \mathrm{~cm}$ de profundidade, fato favorecido pelas pequenas declividades desse ambiente ( $\leq 3 \%$ de declive) e pela presença de horizontes superficiais hísticos (elevados teores de matéria orgânica), responsáveis por grande retenção de água (BALDOCK; NELSON, 1999; OLIVEIRA, 2001; BRADY; WEIL, 1999).

Como o principal componente desse ambiente é o Organossolo Mésico Sáprico térrico, cuja formação está relacionada a forte contribuição de materiais herbáceos em campos saturados hidricamente, não é recomendável o plantio de espécies arbóreas, com exceção da Erythrina crista-galli L., espécie de madeira leve e macia $\left(340 \mathrm{~kg} / \mathrm{m}^{3}\right)$ adaptada aos banhados naturais (BACKES; IRGANG, 2002). Sem dúvida, a baixa densidade da madeira já é uma forte adaptação da espécie a esses tipos de solos com baixa densidade global, pois eles oferecem baixa estabilidade de suporte a espécies arbóreas devido a sua pouca consistência. Fato semelhante se verifica para a Tabebuia cassinoides DC. no litoral paranaense (RACHWAL; CURCIO, 2001).

O ambiente SH (semi-hidromórfico), com declividades variando de 3-8\%, é formado exclusivamente por Cambissolo Húmico Tb Distrófico gleico (Tabela 1), em uma faixa que se estende até aproximadamente $15 \mathrm{~m}$. Dentro dessa faixa, há evidências de processos de redução (gleização) no perfil entre as profundidades de 50 a $100 \mathrm{~cm}$, em função da presença constante do lençol freático.

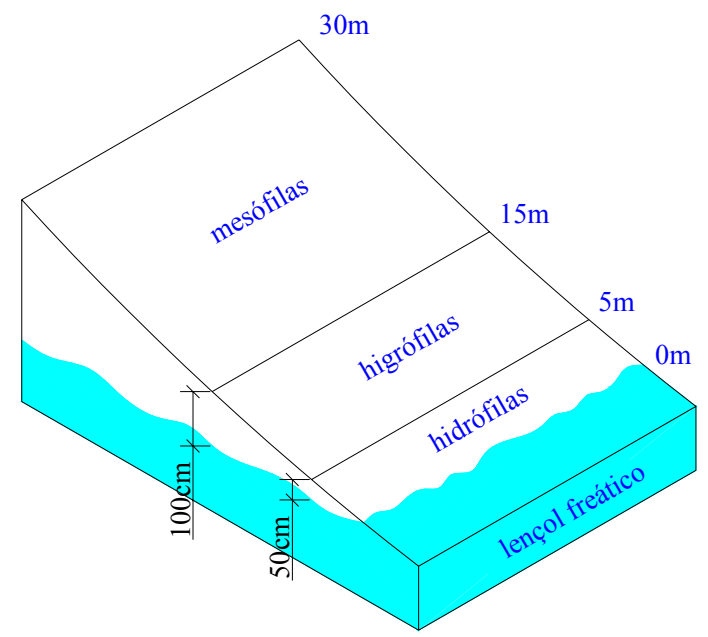

Figura 5. Representação esquemática do lençol freático no ambiente semi-hidromórfico (SH) e indicação de fitotipias.

Figure 5. Schematic representation of water table on low-hydromorphic environment $(\mathrm{H})$ and plants groups recommended.

Feições morfológicas como mosqueados e gleização são bons indicadores para caracterizar os regimes de umidade dos solos (BOUMA, 1983). Dessa forma, na faixa até em torno de $15 \mathrm{~m}$, o solo apresenta boa capacidade de troca gasosa dentro de $50 \mathrm{~cm}$ de profundidade, o que o credencia a receber espécies higrófilas (Figura 5).

De 15 até 30 metros, em função do maior alteamento do solo em relação ao lençol freático, recomenda-se o plantio de espécies mesófilas, embora possam ser utilizadas em menor densidade espécies hidrófilas e higrófilas (Figura 5). Complementarmente, junto ao reservatório (0-5 m) é indicada a utilização de espécies hidrófilas, determinando assim um ambiente de plantio bastante diverso quanto ao regime hídrico dos solos.

De acordo com a figura 6, é possível observar o comportamento do lençol freático, o que justifica uma recomendação diversificada de fitotipias .

$\mathrm{O}$ ambiente NH (não-hidromórfico) é formado por Cambissolos Húmico e Háplico Tb Distróficos típicos (Tabela 1), em relevos com declividade acima de $8 \%$, o que os torna aptos, em sua maior parte, a receber espécies mesófilas. A fím de proporcionar uma maior correspondência ao regime hídrico dos solos, além de garantir uma maior diversidade quanto às fitotipias, é indicado o plantio de espécies hidrófilas próximo à linha d'água, seguido de uma estreita faixa de higrófilas (Figura 7). 


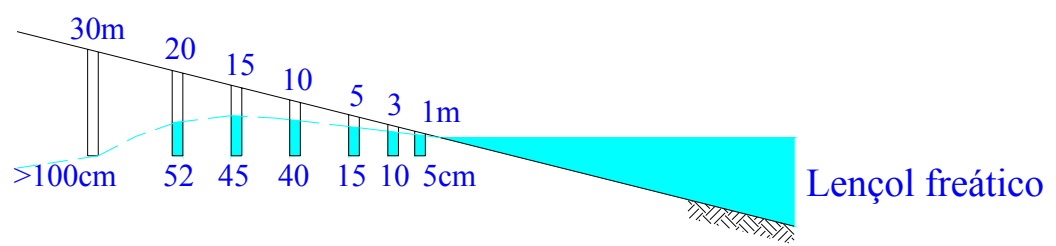

Figura 6. Altura do lençol freático na faixa de $30 \mathrm{~m}$ no ambiente semi-hidromórfico $(\mathrm{SH})$.

Figure 6. Water table level on $30 \mathrm{~m}$ strip width on low-hydromorphic environment.

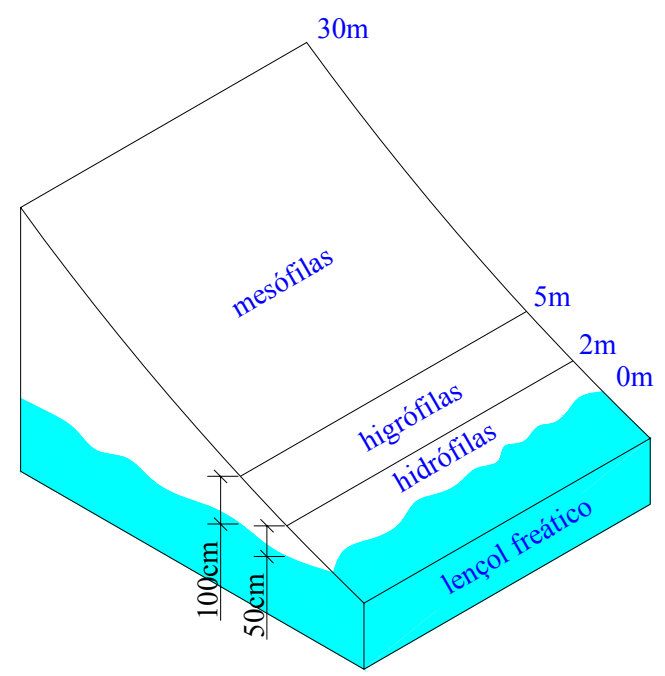

Figura 7. Representação esquemática do lençol freático no ambiente não-hidromórfico $(\mathrm{NH})$ e indicação de fitotipias.

Figure 7. Schematic representation of water table on non-hydromorphic environment (NH) and plants groups recommended. ambiente.

Por intermédio da figura 8 , pode ser observado o comportamento do lençol freático nesse

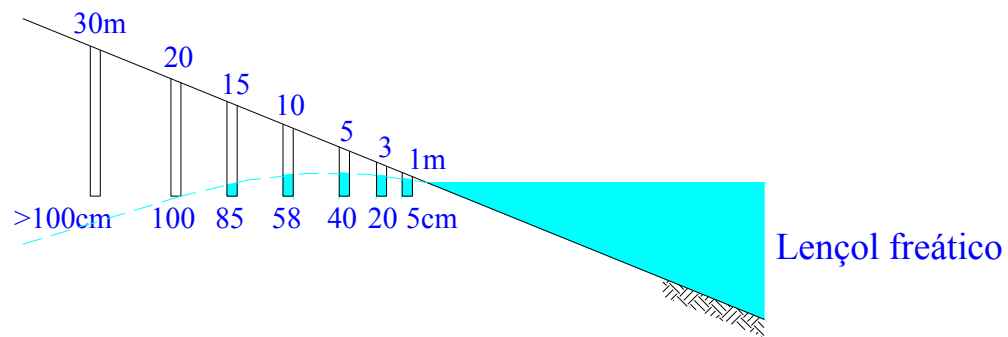

Figura 8. Altura do lençol freático na faixa de $30 \mathrm{~m}$ no ambiente não-hidromórfico $(\mathrm{NH})$.

Figure 8. Water table level on $30 \mathrm{~m}$. strip width on non-hydromorphic environment (NH).

Através dos levantamentos florísticos realizados em capões próximos à represa (Tabela 2), considerando o grau de hidromorfia dos solos, foram identificadas 36 espécies, pertencentes a 24 famílias botânicas, com Myrtaceae e Fabaceae apresentando o maior número de espécies, respectivamente, quatro e três. Somente seis espécies pertencem ao ambiente com solos hidromórficos (hidrófilas), sendo a maioria representante de espécies mesófilas (sobre solos não-hidromórficos). 
Tabela 2. Espécies arbóreas nativas identificadas no levantamento florístico dos capões associadas ao nível de hidromorfia dos solos.

Table 2. Arboreal native species identified on floristic survey of copses associated to hydromorphic level of soils.

\begin{tabular}{|c|c|c|c|c|c|}
\hline \multirow{2}{*}{ Famílias } & \multirow{2}{*}{ Espécies } & \multirow{2}{*}{ Nome comum } & \multicolumn{3}{|c|}{ Solos } \\
\hline & & & $\mathbf{H}^{*}$ & SH* & NH* \\
\hline \multirow[t]{2}{*}{ ANACARDIACEAE } & Lithraea molleoides Engler & bugreiro & - & $\mathrm{x}$ & $\mathrm{x}$ \\
\hline & Schinus terebinthifolius Raddi & aroeira & - & $\mathrm{x}$ & $\mathrm{x}$ \\
\hline AQUIFOLIACEAE & Ilex theezans Mart. & caúna & - & - & $\mathrm{x}$ \\
\hline ARAUCARIACEAE & Araucaria angustifolia (Bertol.) Kuntze & pinheiro-do-paraná & - & - & $\mathrm{x}$ \\
\hline ARECACEAE & Syagrus romanzoffiana (Cham.) Glassman & jerivá & - & $\mathrm{x}$ & $\mathrm{x}$ \\
\hline \multirow[t]{2}{*}{ ASTERACEAE } & Gochnatia polymorpha (Less.) Cabrera & cambará & - & $\mathrm{x}$ & $\mathrm{x}$ \\
\hline & Vernonia discolor (Spreng.) Less. & vassourão-preto & - & - & $\mathrm{x}$ \\
\hline BIGNONIACEAE & Tabebuia alba (Cham.) Sandwith & ipê-amarelo & - & - & $\mathrm{x}$ \\
\hline CANELLACEAE & Capsicodendron dinisii (Schwacke) Occhioni & pimenteira & - & $\mathrm{x}$ & $\mathrm{x}$ \\
\hline ERYTHROXYLACEAE & Erythroxylum argentinum O. E. Schulz & cocão & - & $\mathrm{x}$ & $\mathrm{x}$ \\
\hline \multirow[t]{2}{*}{ EUPHORBIACEAE } & Sapium glandulatum $\mathrm{Pax}$ & leiteiro & - & $\mathrm{x}$ & $\mathrm{x}$ \\
\hline & $\begin{array}{l}\text { Sebastiania commersoniana (Baillon) L.B. Sm. } \\
\text { R.J. Downs }\end{array}$ & branquilho & $\mathrm{x}$ & - & - \\
\hline \multirow[t]{3}{*}{ FABACEAE } & Erythrina crista-galli L. & corticeira-do-banhado** & $\mathrm{x}$ & - & - \\
\hline & Erythrina falcata Benth. & corticeira-do-mato & - & $\mathrm{x}$ & $\mathrm{x}$ \\
\hline & Machaerium stipitatum Vog. & sapuva & - & $\mathrm{x}$ & $\mathrm{x}$ \\
\hline \multirow[t]{2}{*}{ FLACOURTIACEAE } & Casearia sylvestris $\mathrm{Sw}$. & guaçatunga & - & $\mathrm{x}$ & $\mathrm{x}$ \\
\hline & Xylosma pseudosalzmannii Sleumer & sucará & $\mathrm{x}$ & $\mathrm{x}$ & $\mathrm{x}$ \\
\hline LYTHRACEAE & Lafoensia pacari St.-Hil. & dedaleiro & - & - & $\mathrm{x}$ \\
\hline MIMOSACEAE & Mimosa scabrella Benth. & bracatinga & - & - & $\mathrm{x}$ \\
\hline \multirow[t]{2}{*}{ MYRSINACEAE } & Myrsine coriacea R.Br. & capororoquinha & - & $\mathrm{x}$ & $\mathrm{x}$ \\
\hline & Myrsine umbellata G. Don & capororoca & - & $\mathrm{x}$ & $\mathrm{x}$ \\
\hline \multirow[t]{4}{*}{ MYRTACEAE } & Blepharocalyx salicifolius (Kunth) O. Berg & murta & $\mathrm{x}$ & $\mathrm{x}$ & - \\
\hline & Myrciaria tenella (DC.) O. Berg & cambuí & $\mathrm{x}$ & $\mathrm{x}$ & $\mathrm{x}$ \\
\hline & Campomanesia xanthocarpa O. Berg & guabirobeira & - & $\mathrm{x}$ & $\mathrm{x}$ \\
\hline & Psidium cattleianum Sabine & araçazeiro & - & $\mathrm{x}$ & $\mathrm{x}$ \\
\hline \multirow[t]{2}{*}{ LAURACEAE } & Nectandra grandiflora Ness e Mart. ex Ness & canela-amarela & - & - & $\mathrm{x}$ \\
\hline & Ocotea pulchella Mart. & canela-lageana & - & $\mathrm{x}$ & $\mathrm{x}$ \\
\hline PODOCARPACEAE & Podocarpus lambertii Klotz ex Endl. & pinheiro-bravo & - & $\mathrm{x}$ & $\mathrm{x}$ \\
\hline RUBIACEAE & Rudgea jasminoides (Cham.) Müll. Arg. & pimenteira & - & $\mathrm{x}$ & $\mathrm{x}$ \\
\hline RUTACEAE & $\begin{array}{l}\text { Zanthoxylium kleinii (R.S. Cowan) P. G. } \\
\text { Waterman }\end{array}$ & mamica-de-cadela & - & - & $\mathrm{x}$ \\
\hline \multirow[t]{2}{*}{ SAPINDACEAE } & Allophylus edulis Radlk. Ex Warm. & vacum & - & $\mathrm{x}$ & $\mathrm{x}$ \\
\hline & Matayba elaeagnoides Radlk. & miguel-pintado & - & - & $\mathrm{x}$ \\
\hline SAXIFRAGACEAE & Escallonia montevidensis PC. & canudo-de-pito & $\mathrm{x}$ & $\mathrm{x}$ & - \\
\hline SOLANACEAE & Solanum granulosum-leprosum Dunal & fumo-bravo & - & - & $\mathrm{x}$ \\
\hline TILIACEAE & Luehea divaricata Mart. & açoita-cavalo & - & $\mathrm{x}$ & $\mathrm{x}$ \\
\hline VERBENACEAE & Vitex megapotamica (Spreng.) Moldenke & tarumã & - & - & $\mathrm{x}$ \\
\hline
\end{tabular}

*H: hidromórfico; $\mathrm{SH}$ : semi-hidromórfico; $\mathrm{NH}$ : não-hidromórfico.

**espécie encontrada somente em campos hidrófilos.

A recomendação de plantio abaixo relacionada (Tabela 3) resulta de uma interação do conhecimento dos autores sobre a adaptabilidade das espécies aos diferentes tipos de solos e do conteúdo presente na tabela 2. Depreende-se, portanto, uma recomendação de plantio escalonada em etapas, respeitando o enquadramento dos grupos ecológicos (REITZ et al., 1978; INOUE et al., 1984; REITZ et al., 1988; LORENZI, 1992; LORENZI, 1998; CARVALHO, 2003) a que pertencem.

Deve ser ressaltado que indivíduos representantes da fitotipia higrófila podem ser plantados em solos não-hidromórficos, apresentando bom desenvolvimento.

Recomenda-se ainda, com vistas a proporcionar dificuldades de acesso aos plantios por parte das pessoas, o enriquecimento adensado na bordadura dos plantios com sucará (Xilosma pseudosalzmannii Sleumer), espécie com fuste muito rico em espinhos de grande porte. Tendo em vista o possível corte de árvores, é interessante efetuar o plantio de Dalbergia frutescens (Vell.) Britton (rabo-de-bugiu), espécie nativa de hábito trepador que proporciona o entrelaçamento das copas árvores, dificultando sobremaneira a queda delas. 
Tabela 3. Recomendação de espécies pioneiras e climácicas por grau de saturação hídrica do solo. Table 3. Pioner and climax species recomended by level of soil water saturation.

\begin{tabular}{lccc}
\hline \multirow{2}{*}{ Grupos ecológicos } & \multicolumn{2}{c}{ Fitotipias quanto ao grau de saturação hídrica do solo } \\
\cline { 2 - 4 } & Hidrófilas & Higrófilas & Mesófilas \\
\hline Pioneiras & branquilho & açoita-cavalo & bracatinga \\
& canudo-de-pito & araçá & dedaleiro \\
& corticeira-do-banhado & aroeira & fumo-bravo \\
& & leiteiro & guaçatunga \\
\hline Climácicas* & Murta & cambará & erva-mate \\
& & canela-lageana & ipê-amarelo \\
& & guabirobeira & miguel-pintado \\
& & pinheiro-bravo & pinheiro-do-paraná \\
& & tarumã & \\
\hline * inclui espécies climácicas tolerantes à sombra e climácicas exigentes em luz. &
\end{tabular}

\section{CONCLUSÕES}

A metodologia adotada possibilita a recomendação de espécies arbóreas nativas adaptadas a diferentes regimes hídricos de solos, permitindo, portanto, melhor desenvolvimento e maior grau de sobrevivência das plantas.

O direcionamento de plantio de espécies arbóreas nativas conforme o seu grau de adaptabilidade aos diferentes regimes hídricos dos solos possibilita uma sensível redução de custos, principalmente nas operações de replantio e de manutenção das mudas.

\section{REFERÊNCIAS}

BACKES, P.; IRGANG, B. Árvores do Sul: guia de identificação e interesse ecológico. Porto Alegre: Clube da Árvore, 2002. 325p.

BALDOCK, J. A.; NELSON, P. N. Soil organic matter. In: SUMNER, M. E. (Ed.) Handbook of Soil Science. Boca Ratom, v. 1, p. 25-71, 1999.

BARDDAL, M. L. Aspectos florísticos e fitossociológicos do componente arbóreo-arbustivo de uma Floresta Ombrófila Mista Aluvial - Araucária, PR. 90f. Dissertação (Mestrado) - Setor de Ciências Agrárias, Universidade Federal do Paraná, Curitiba, 2002.

BARDDAL, M. L.; PROTIL, C. Z.; SOUZA, S. G. A. de. Fitossociologia do componente arbóreo de um trecho da planície do rio Iraizinho, Piraquara, Paraná, Brasil. Revista Estudos de Biologia, Curitiba, v. 25 , n. 53, p. 17-28, out./dez, 2003.

BIGARELlA. J. J.; SALAMUNI, J.; AB’SABER, A. N. Origem e ambiente de deposição da Bacia de Curitiba. Boletim Paranaense de Geografia. Curitiba, n. 4/5. p. 71-81, 1961.

BIGAREllA, J. J.; SAlAMUNI, J. R. Caracteres texturais dos sedimentos da Bacia de Curitiba. Boletim da UFPR. Geologia. Curitiba, n. 7. p. 1-164. 1962.

BOUMA, J. Hydrology and soil genesis of soils with aquic moisture regimes. In: WILDING, L. P.; SMECK, N. C.; HALL, G. F. Pedogenesis and soil taxonomy: concepts and interactions. Amsterdam: Elsevier Science, 1983. 253-281p.

BRADY, N. C.; WEIL, R. R. The nature and properties of soils. 12.ed. Upper Saddle River: Prentice Hall, 1999. 881p.

BRASIL. Lei n $\mathrm{n}^{\mathrm{0}}$ 4.771, de 15 de setembro de 1965. Institui o Novo Código Florestal. In: VENTURA, J. V.; RAMBELLI, A. M. Legislação federal sobre o meio ambiente. 3.ed. Taubaté: Vana, 1999. p. 200211.

BRINSON, M. M. Riverine forests. In: LUGO, A. E.; BRINSON, M.; BROWN, S. Ecosystems of the world 15 - Forested wetlands. Amsterdam: Elsevier Science, 1990. p. 87-142. 
BUFREM, A. M. Caracterização fitossociológica de um remanescente da floresta ripária do rio Pequeno, São José dos Pinhais - PR. 87f. Dissertação (Mestrado) - Setor de Ciências Biológicas, Universidade Federal do Paraná, Curitiba, 1997.

CARNEIRO, C.; PEGORINI, E. S.; ANDREOLli, C. V. Introdução. In: ANDREOLli, C. V.; CARNEIRO, C. (Eds.). Gestão Integrada de mananciais de abastecimento eutrofizados. Curitiba: Gráfica Capital, 2005. p. 25-44.

CARVALHO, P. E. R. Espécies arbóreas brasileiras. Brasília: Embrapa Informação Tecnológica, 2003. $1039 \mathrm{p}$.

CASANOVA, M. T.; BROCK, M. A. How do depth, duration and frequency of flooding influence the establishment of wetland plant communities? Plant Ecology, Dordrecht, n. 147, p. 237-250, 2000.

CONSELHO NACIONAL DO MEIO AMBIENTE. Resolução $n^{0}$ 302, de 2002. Dispõe sobre os parâmetros, definições e limites de Áreas de Preservação Permanente de reservatórios artificiais e o regime de uso do entorno. Disponível em: <www.mma.gov/br/port/conama/res/res02/res30202.html>. Acesso em: $11 \mathrm{dez} .2005$.

CURCIO, G. R. Relações entre geologia, geomorfologia, pedologia e fitossociologia nas planícies fluviais do rio Iguaçu, Paraná, Brasil. 488p. Tese (Doutorado em Engenharia Florestal) - Setor de Ciências Agrárias, Universidade Federal do Paraná, Curitiba, 2006.

CURCIO, G. R.; RACHWAL, M. F. G.; CARDOSO, A. DEDECEK, R. A.Levantamento semidetalhado de solos das planícies do município de Piraquara, estado do Paraná. Colombo: Embrapa Florestas, [2006?]. 93p. Não publicado.

IAPAR. Cartas climáticas do Estado do Paraná. Londrina: IAPAR. 1994. 49p. (Documento, n. 18).

InOUE, M. T.; RODERJAN, C. V.; KUNIYOSHI, Y. S. Projeto Madeira do Paraná. Curitiba: Fundação de Pesquisas Florestais do Paraná, 1984. 260p.

KOZLOWSKI, T. T. Extent, causes and impacts of flooding. In: KOZLOWSKI, T. T. Flooding and plant growth. Orlando: Academic, 1984. p.1-7.

LORENZI, H. Árvores brasileiras: manual de identificação e cultivo de plantas arbóreas nativas do Brasil. Nova Odessa, SP: Editora Plantarum. v. 1. 1992. 352p.

LORENZI, H. Árvores brasileiras: manual de identificação e cultivo de plantas arbóreas nativas do Brasil. Nova Odessa, SP: Editora Plantarum. v. 2. 1998. 352p.

MAACK, R. Geografia Física do Estado do Paraná. 2.ed. Curitiba: Ed. Olympio, 1981. 450p.

MIRANDA, E. D. de. A água na natureza e na vida dos homens. Aparecida: Idéias e Letras. 2004. 141p.

OLIVEIRA, J. B. (b) Pedologia aplicada. Jaboticabal: FUNEP, 2001. 414p.

PASDIORA, A. L. Florística e fitossociologia de um trecho de floresta ripária em dois compartimentos ambientais do rio Iguaçu, Paraná, Brasil.. 47f. Dissertação (Mestrado em Ciências Florestais) - Setor de Ciências Agrárias, Universidade Federal do Paraná, Curitiba, 2003.

RACHWAL, M. F. G.; CURCIO, G. R. Atributos pedológicos e ocorrência de caixeta no litoral paranaense, Brasil. Scientia Forestalis, Piracicaba, n. 59, p. 153-163, 2001.

REITZ, R.; KLEIN, R. M.; REIS, A. Projeto Madeira de Santa Catarina. Itajaí: SUDESUL/Governo SC/ HBR, 1978. 320p.

REITZ, R.; KLEIN, R. M.; REIS, A. Projeto Madeira do Rio Grande do Sul. [S.1.]: SUDESUL/Governo RS/ HBR, 1988. 525p.

RODERJAN, C. V.; GALVÃO, F.; KUNIYOSHI, Y. S.; HATSCHBACK, G. As unidades fitogeográficas do Estado do Paraná. Ciência e Ambiente, Santa Maria, v. 24, p. 75-92, jan./jun, 2002.

ZILLER, S. As formações vegetais da área de influência do futuro reservatório do rio Iraí Piraquara, Quatro Barras - Paraná. Curitiba: IAP. 1995. 87p. 